\title{
The Use of MALDI-TOF Mass Spectrometry, Ribotyping and Phenotypic Tests to Identify Lactic Acid Bacteria from Fermented Cereal Foods in Abidjan (Côte d'Ivoire)
}

\author{
Amenan A. Soro-Yao ${ }^{1, *}$, Peter Schumann ${ }^{2}$, Philippe Thonart $^{3,4}$, Koffi M. Djè ${ }^{1}$ and Rüdiger Pukall ${ }^{2}$ \\ ${ }^{I}$ Food Science and Technology Unit, Nangui Abrogoua University, 02 BP 801 Abidjan 02, Côte d'Ivoire \\ ${ }^{2}$ Leibniz-Institute DSMZ-German Collection of Microorganisms and Cell Cultures, 38124 Braunschweig, Germany \\ ${ }^{3}$ Wallon Center for Industrial Microbiology (CWBI), University of Liège, Bld du Rectorat 29-B40, B 4000 Liège, \\ Belgium \\ ${ }^{4}$ Wallon Center of Industrial Biology, Bio-industry Unit, Gembloux Agro-BioTech, 5030 Gembloux, Belgium
}

\begin{abstract}
Matrix-assisted laser desorption/ionization time-of-flight mass spectrometry (MALDI-TOF MS) protein analysis, automated ribotyping, and phenotypic tests (e.g., cell morphology, gas production from glucose, growth and acid production on homofermemtative-heterofermentative differential (HHD) agar medium, sugar fermentation patterns) were used to identify 23 lactic acid bacteria (LAB) isolated from fermented cereal foods available in Abidjan, Côte d'Ivoire. Pediococcus acidilactici (56.5\%), Lactobacillus fermentum (30.4\%), L. salivarius (4.3\%), P. pentosaceus (4.3\%) and $L$. plantarum subsp. plantarum (4.3\%) were the species and subspecies identified. Protein based identification was confirmed by automated ribotyping for selected isolates and was similar to that provided by the phenotypic characterization. MALDI-TOF MS protein analysis provided a high level of discrimination among the isolates and could be used for the rapid screening of LAB starter cultures.
\end{abstract}

Keywords: Cereal foods, fermentation, food microbiology, lactic acid bacteria, MALDI-TOF MS, ribotyping, species identification, starter cultures.

\section{INTRODUCTION}

Fermented cereal foods offer West African consumers an affordable source of food and make a significant contribution to their food and nutritional security. Examples of these foods in Côte d'Ivoire include baca or wômi [1, 2]. Like other fermented cereal foods available in the region, these products suffer from inconsistent quality. With increasing urbanization, efforts are currently geared towards developing small-scale facilities for producing fermented cereal foods where the quality of the finished product will be assured. The development and improvement of inoculants containing high concentrations of live microorganisms, referred to as starter cultures, is a subject of increasing interest in efforts to standardize the fermentation step [2]. The use of dried starter cultures has already been shown to be of great use in smallscale processing units [3].

In order to provide West African consumers with fermented products of consistent quality, the microbiology of many fermented cereal foods has been investigated. These investigations indicate that the fermentation was natural and

\footnotetext{
*Address correspondence to this author at the Food Science and Technology Unit, Nangui Abrogoua University, 02 BP 801 Abidjan 02, Côte d'Ivoire; Tel: +225 45008631; Fax: +225 31202034; E-mail: amenansoro@yahoo.fr
}

involved mixed cultures of lactic acid bacteria (LAB), yeasts and fungi. The lactic acid bacteria species identified were Lactobacillus fermentum, L. plantarum, L. salivarius, $L$. delbrueckii, L. amylolyticus, $L$. reuteri, L. paraplantarum, Lactococcus lactis, Leuconostoc mesenteroides, Pediococcus acidilactici, P. pentosaceus, Streptococcus gallolyticus and Weissella confusa [4-11]. Species identification was performed using phenotypic tests such as cell morphology, sugar fermentation patterns and gas production from glucose, as well as molecular typing techniques, including polymerase chain reaction (PCR), repetitive PCR (RepPCR), 16S rRNA sequencing, denaturing gradient gel electrophoresis (DGGE), PCR-DGGE fingerprinting, multilocus sequence analysis (MLSA), intergenic transcribed spacers (ITS)-PCR, restriction fragment length polymorphism (RFLP) and restriction enzyme analysis with pulsed-field gel electrophoresis (REA-PFGE). Although these procedures provide good discriminatory power and accuracy, most of them are labor-intensive, time-consuming, expensive and difficult to carry out in routine analysis $[12,13]$. In addition, identification based on morphological and biochemical tests has been reported to be limited to the genus or species level and to have poor reproducibility and discriminatory power $[14,15]$. 
The selection of $\mathrm{LAB}$ as dried starter cultures for cereal fermentation is a complex process, involving the identification as well as the evaluation of some desired metabolic traits and technological performance. The use of an innovative, rapid and accurate technique to identify LAB isolates could be useful for improving the processing of fermented cereal foods. Matrix-assisted laser desorption/ ionization time-of-flight mass spectrometry (MALDI-TOF MS) is a chemotaxonomic method in which LAB species are identified based on mass spectra patterns of ribosomal proteins $[16,17]$. Short turnaround times, low reagent costs or sample volume requirements and the ease of conducting in routine analysis are some of the major advantages that have been reported. Despite high instrument cots, proteomic identification using MALDI-TOF MS is being increasingly used to identify food-associated bacteria such as LAB starter cultures. Lactobacillus plantarum, $L$. fermentum, $P$. acidilactici and $P$. pentosaceus have been accurately identified in fermented vegetables and meat in Vietnam [12, 18]. Bifidobacterium animalis, L. delbrueckii, L. casei, Lact. lactis and $S$. thermophilus species or subspecies have been successfully differentiated in probiotic foods and yoghurts [19-21]. MALDI-TOF MS protein analysis could be used alone or in combination with a molecular method such as ribotyping in order to differentiate closely related species $[14,22]$. Ribotyping is a molecular typing method, which can be performed automatically using the RiboPrinter ${ }^{\circledR}$ microbial characterization system (Qualicon TM, USA). Three Lactobacillus paracasei, two Enterococcus faecalis and one L. plantarum types from Portuguese cheese [23], as well as many other LAB species types [15], have been discriminated using automated ribotyping.

With regard to identifying $\mathrm{LAB}$ from African fermented foods, although the use of phenotypic and genotypic methods have often been reported, no detailed information is available on their proteomic identification using MALDITOF MS. This work sought to evaluate the use of MALDITOF MS protein analysis for the identification of twentythree $\mathrm{LAB}$ isolated from fermented cereal foods available in Abidjan. Automated ribotyping and phenotypic tests were used to confirm the identity of selected isolates and all the isolates, respectively.

\section{MATERIAL AND METHODS}

\section{Sample Collection and Isolation Procedure}

Millet gruel (baca), fermented millet dough for wômi production and fried millet cake (wômi) samples were collected from street and market sellers in Abidjan. Microbial isolation was performed on MRS agar containing $3.0 \mathrm{~g}$ calcium carbonate at $30^{\circ} \mathrm{C}$. Fifty-five isolates were obtained and were purified by continued streaking on MRS calcium carbonate agar. An initial screening of the 55 isolates was carried out based on their growth parameters $\left(\mathrm{pH}, \mathrm{OD}_{600 \mathrm{~nm}}\right.$, cell concentration) after $18 \mathrm{~h}$ culture on MRS broth. Twenty-three broth cultures showed a $\mathrm{pH} \leq 4.5$, an $\mathrm{OD}_{600 \mathrm{~nm}} \geq 2$ and cell concentration $\geq 5 \times 10^{10} \mathrm{cfu} / \mathrm{g}$ dry weight, and the corresponding presumptive LAB were selected for identification. The selected isolates were purified by continued streaking on trypticase/soy/yeast extract agar (medium 92, German Collection of Microorganisms and Cell Cultures [DSMZ] Catalogue of Strains). Microscopic examinations and plate counts on MRS agar were used to check the purity of the isolates. Each isolate was inoculated in MRS broth and stored at $30^{\circ} \mathrm{C}$ for 18 h. A Microbank ${ }^{\mathrm{TM}}$ (Pro-Lab Diagnostics, Richmond Hill, Canada) of each isolate was obtained following the manufacturer's instructions, and then stored at $-20^{\circ} \mathrm{C}$.

\section{Phenotypic Characterizations}

The isolates were characterized by cell morphology using an Axio Scope.A1 (Carl-Zeiss, Oberkochen, Germany) phase-contrast microscope equipped with an Axio Cam MRc5 (Carl-Zeiss, Oberkochen, Germany) camera. Gas production from glucose was assessed on MRS broth supplemented with Durham tubes [24]. Growth and acid production were determined after 3-day incubation at $30^{\circ} \mathrm{C}$ on homofermentative-heterofermentative differential (HHD) agar medium [25]. The sugar fermentation patterns of the isolates were determined using the API $50 \mathrm{CHL}$ test (Biomerieux, Marcy l'étoile, France) and following the manufacturer's instructions.

\section{MALDI-TOF MS Protein Analysis}

MALDI-TOF MS protein analysis was carried out using a MALDI Bio-Typer (Bruker Daltonics, Karlsruhe, Germany) as described previously [26]. Biomasses on Trypticase/soy/yeast extract agar (medium 92, DSMZ Catalogue of Strains) were subjected to an ethanol/formic acid extraction. Cell extracts obtained were added with a matrix solution $(1.5 \mathrm{ml}$; saturated solution of $\alpha$-cyano-4hydroxycinnamic acid in 50\% aqueous acetonitrile containing $2.5 \%$ trifluoroacetic acid) and dried. Proteomic analysis was performed using a Microflex L20 mass spectrometer (Bruker Daltonics, Germany) equipped with an $\mathrm{N} 2$ laser and a mass range of 2,000-20,000 m/z was used for analysis. The MALDI-TOF mass spectra were analyzed with MALDI-bioTyper 3.0 software (Bruker Daltonics, Karlsruhe, Germany). The results were expressed by MALDI-bioTyper matching scores (ranging from 0.000 to 3.000), which indicated the similarity of the unknown MALDI-TOF MS profile to available profiles on the MALDI-bioTyper 3.0 software database. Proteomic identification was approved for an isolate with a matching score of more than 2.000. A score-oriented MALDI-TOF MS dendogram was created using MALDI-bioTyper 3.0 software (Bruker Daltonics, Karlsruhe, Germany).

\section{Automated Ribotyping}

Automated ribotyping of DNA fragments obtained from EcoRI-digested UN3, UN5, UN6, UN20, UN25, UN26, UN32, UN35 and UN47 cells were carried out using the RiboPrinter ${ }^{\circledR}$ microbial characterization system (Qualicon TM, Wilmington, USA) as described previously [27, 28]. The ribopatterns obtained were compared to previously run reference patterns by using the Pearson similarity coefficient and the unweighted pair-group method with arithmetic averages (UPGMA). 


\section{RESULTS AND DISCUSSION}

MALDI-TOF MS protein and automated ribotyping, alongside phenotypic tests (e.g., cell morphology, gas production from glucose, growth and acid production on HHD agar medium, and sugar fermentation patterns) were used to identify $23 \mathrm{LAB}$ isolated from fermented cereal foods available in Abidjan. MALDI-TOF mass spectra profiles of the 23 isolates were compared with those of reference strains in the MALDI-bioTyper 3.0 database (Fig. 1). Thirteen isolates formed a cluster with the type strain of $P$. acidilactici DSM $20284^{\mathrm{T}}$ and there was low diversity in this group. The isolate UN32 appeared as the sister group of these 13 isolates and showed spectra that were similar to the type strain of $P$. pentosaceus DSM $20336^{\mathrm{T}}$. The isolates UN47 and UN6 were set well apart and formed two distinct clusters with type strains of $L$. plantarum subsp. plantarum DSM $20174^{\mathrm{T}}$ and L. salivarius DSM $20555^{\mathrm{T}}$. Seven isolates formed clusters nearby the $L$. fermentum type strain DSM $20052^{\mathrm{T}}$. There was high diversity among these isolates, with six distinct mass spectra profiles observed in the same cluster. Among the 23 isolates identified by MALDI-TOF MS protein analysis, nine isolates were further subjected to automatic EcoRI ribotyping. The resulting patterns for four Pediococcus and five Lactobacillus isolates are shown in Figs (2 and $\mathbf{3})$, respectively. The isolate UN32 showed $92 \%$ similarity with the type strain of $P$. pentosaceus DSM $20336^{\mathrm{T}}$. The similarity between UN20, UN25, UN26 and the type strain of P. acidilactici DSM $20284^{\mathrm{T}}$ exceeded $90 \%$. The isolate UN47 was identified at the subspecies level, showing a similarity of $95 \%$ with the $L$. plantarum subsp. argentoratensis type strain DSM $16365^{\mathrm{T}}$ (type strain of the

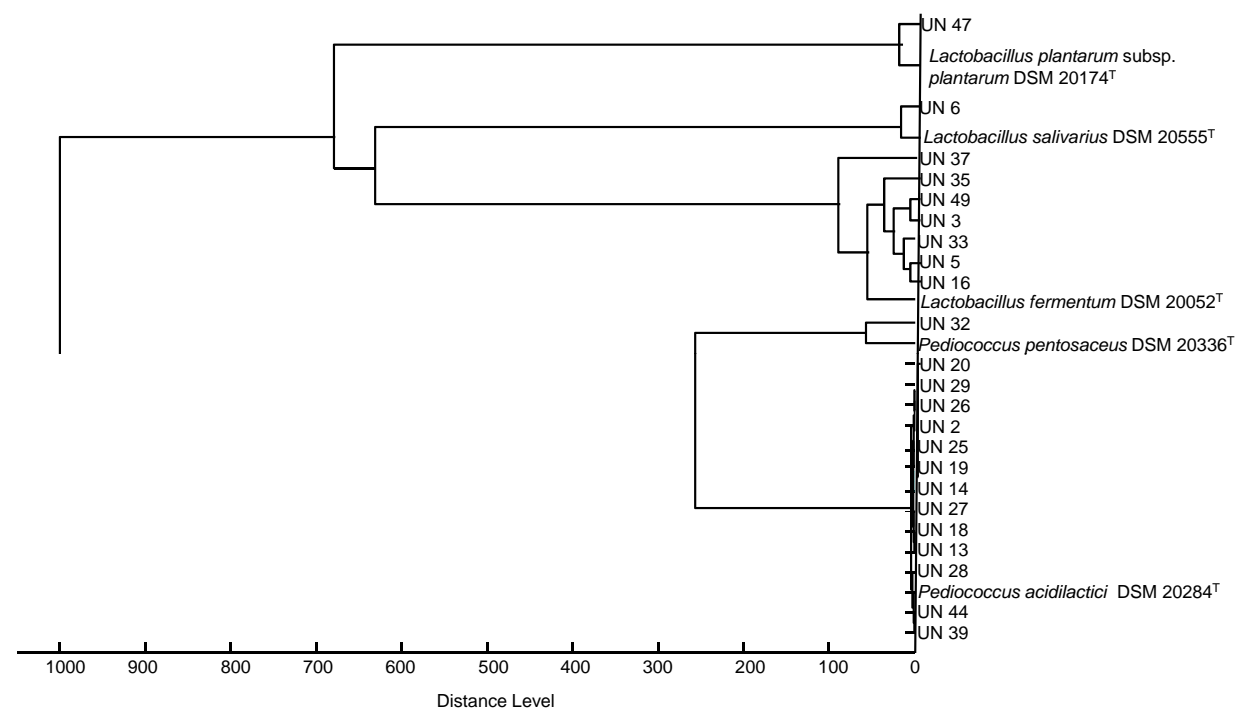

Fig (1). Score-oriented dendogram showing the similarity of the MALDI-TOF mass spectra of 23 LAB isolates and reference strains from the MALDI-bioTyper 3.0 database: Pediococcus acidilactici DSM 20284 ${ }^{\mathrm{T}}$, P. pentosaceus DSM 20336 ${ }^{\mathrm{T}}$, Lactobacillus fermentum DSM $20052^{\mathrm{T}}$, L. salivarius DSM $20555^{\mathrm{T}}$ and L. plantarum subsp. plantarum DSM $20174^{\mathrm{T}}$. The dendogram was created with BioTyper 3.0 software (Bruker Daltonics, Karlsruhe, Germany).

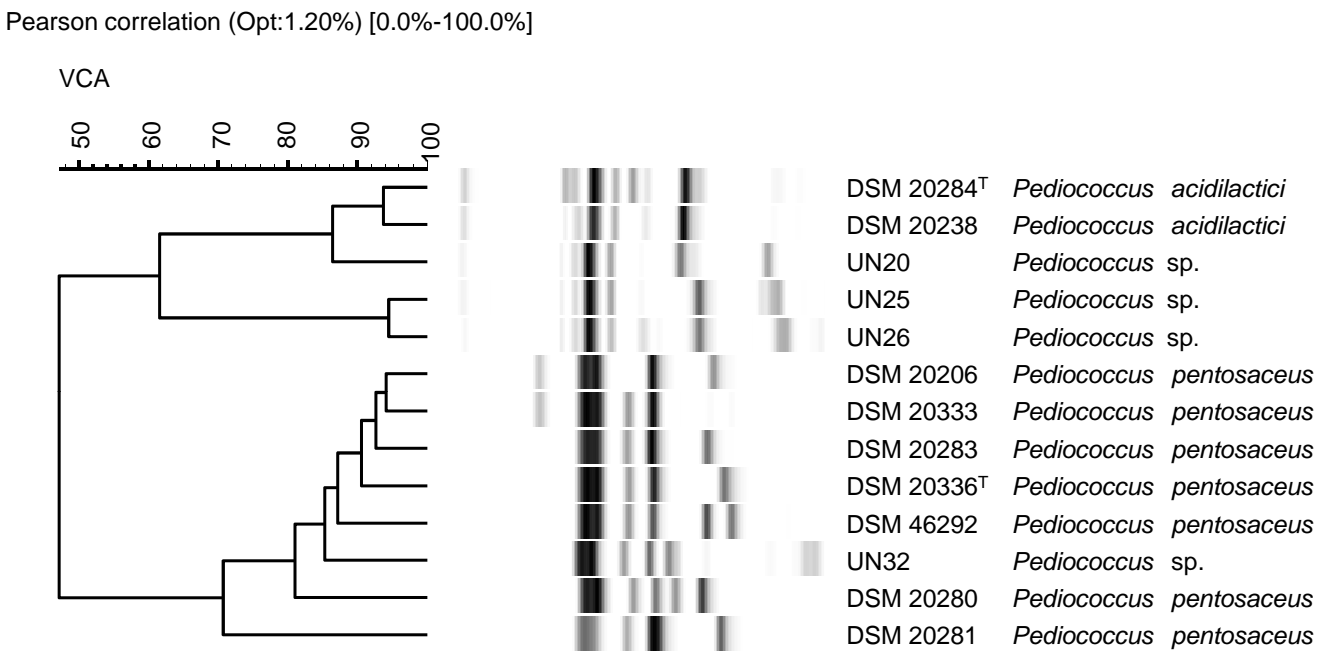

Fig. (2). Riboprint patterns of the isolates UN20, UN25, UN26 and UN32. Cluster analysis was performed by UPGMA based on the Pearson correlation (Opt: $1.20 \%$ ) [0.0\%-100.0\%]. VCA indicates a standard EcoRI batch. The molecular masses of the bands range from $1 \mathrm{~kb}$ (right) to $60 \mathrm{~kb}$ (left). 
Pearson correlation (Opt:1.56\%) [0.0\%-100.0\%]

VCA

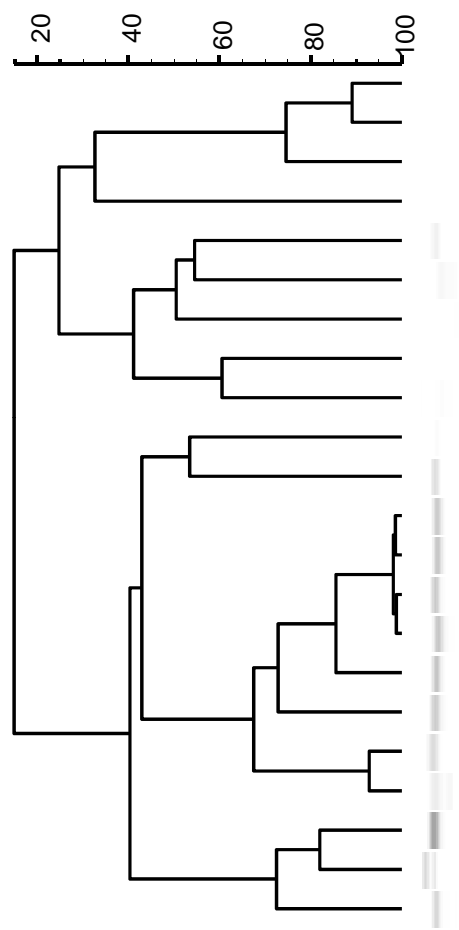

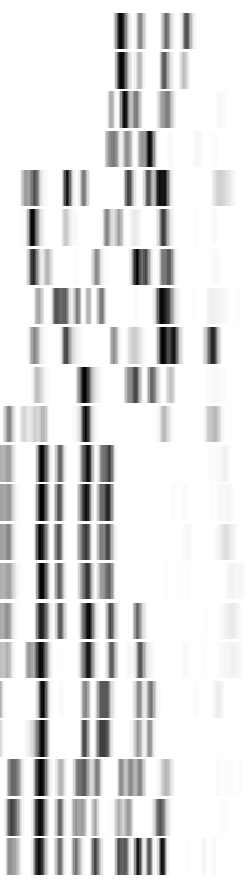

$\begin{array}{lll}\text { DSM 20016 } & \text { Lactobacillus } & \text { reuteri } \\ \text { DSM } 8534 & \text { Lactobacillus } & \text { reuteri } \\ \text { DSM } 20056 & \text { Lactobacillus } & \text { reuteri } \\ \text { DSM } 20015 & \text { Lactobacillus } & \text { reuteri } \\ \text { DSM } 20391 & \text { Lactobacillus } & \text { fermentum } \\ \text { UN5 } & \text { Lactobacillus } & \text { sp. } \\ \text { UN3 } & \text { Lactobacillus } & \text { sp. } \\ \text { DSM 20055 } & \text { Lactobacillus } & \text { fermentum } \\ \text { UN35 } & \text { Lactobacillus } & \text { sp. } \\ \text { DSM 20052 } & \text { Lactobacillus } & \text { fermentum } \\ \text { DSM 10667' } & \text { Lactobacillus } & \text { paraplantarum } \\ \text { DSM 20246 } & \text { Lactobacillus } & \text { plantarum } \\ \text { DSM 2648 } & \text { Lactobacillus } & \text { plantarum } \\ \text { DSM 20174 } & \text { Lactobacillus } & \text { plantarum } \\ \text { DSM 2601 } & \text { Lactobacillus } & \text { plantarum } \\ \text { DSM 12028 } & \text { Lactobacillus } & \text { plantarum } \\ \text { DSM 20205 } & \text { Lactobacillus } & \text { plantarum } \\ \text { DSM 16365' } & \text { Lactobacillus } & \text { plantarum subsp. argentoratensis } \\ \text { UN47 } & \text { Lactobacillus } & \text { sp. } \\ \text { DSM20554 } & \text { Lactobacillus } & \text { salivarius } \\ \text { DSM20555 } & \text { Lactobacillus } & \text { salivarius } \\ \text { UN6 } & \text { Lactobacillus } & \text { sp. }\end{array}$

Fig. (3). Riboprint patterns of the isolates UN3, UN5, UN6, UN35 and UN47. Cluster analysis was performed by UPGMA based on the Pearson correlation (Opt: 1.56\%) [0.0\%-100.0\%]. VCA indicates a standard EcoRI batch. The molecular masses of the bands range from $1 \mathrm{~kb}$ (right) to $60 \mathrm{~kb}$ (left).

subspecies L. plantarum subsp. plantarum is DSM $20174^{\mathrm{T}}$ ). Isolate UN 6 could be identified as Lactobacillus salivarius by automated ribotyping. Further on the analysis revealed that the Lactobacillus fermentum group formed several clusters also distantly related to the type strain DSM $20052^{\mathrm{T}}$. Proteomic identification was confirmed by automated ribotyping of selected isolates. A clear differentiation between related L. fermentum species, which showed high diversity among them, was achieved. This had been previously reported in a MALDI-TOF MS protein analysis of L. fermentum species isolated from fermented dua mиоi and ca muoi [18]. Our results showed great homogeneity within the $P$. acidilactici strains as analysed on the protein and DNA (ITS spacer region) level.

Pediococcus acidilactici (57\%) and L. fermentum (30\%) were the dominant species identified from fermented cereal based foods of Abidjan. Pediococcus acidilactici and $L$. fermentum have been reported to be the dominant species in other fermented cereal foods in West Africa [5-8, 10, 11]. Lactobacillus salivarius, P. pentosaceus, and L. plantarum have been reported to be less dominant species in mawè [5], ogi [8] and ben-saalga [29] processing, respectively. Others studies have reported that $P$. pentosaceus is one of the main species in koko or fura [6, 10] and gowé [11] processing. Differences in fermentation length, initial number of microorganisms present in the raw material used, type of containers used for fermentation, and climatic conditions of the local area could explain variations in species proportions among the various fermented cereal foods.
The isolates were tentatively identified using phenotypic tests such as cell morphology, $\mathrm{CO}_{2}$ formation from glucose, and growth and acid production on HHD agar medium (Tables 1, 2, Fig. 4). The coccoid-shaped isolates accounted for $61 \%$ (14 isolates), whereas the rod-shaped ones accounted for $39 \%$ (9 isolates) of the population. About $70 \%$ (16 isolates) of the isolates were unable to produce gas from glucose, indicating that they were homofermentative strains. All the other isolates, accounting for $30 \%$ (seven isolates), were related to heterofermentative species. Obligately homofermentative colonies were blue on an acidified HHD agar and were recorded as positive for the test (+) (Fig. 4a). Facultatively homofermentative colonies were white with a blue spot on an acidified HHD agar and were recorded as negative/positive $(-/+)$ for the test (Figure $4 \mathbf{b})$. Obligately heterofermentative colonies were white on a blue HHD agar (medium without acidification) and were recorded as negative (-) for the test (Fig. 4c). All the coccoid-shaped isolates were related to homofermentative species not able to produce $\mathrm{CO}_{2}$, whereas $78 \%$ (7 isolates) of the rod-shaped isolates were related to obligately heterofermentative species. The isolates UN47 and UN6 were related to facultatively homofermentative and obligately homofermentative rod-shaped species, respectively. The isolates belonged to homofermentative coccoid-shaped $(P$. acidilactici, $P$. pentosaceus), obligately heterofermentative rod-shaped (L. fermentum), facultatively homofermentative rod-shaped (L. plantarum subsp. plantarum) and obligately homofermentative rod-shaped ( $L$. salivarius) species (Tables 1, 2). 
Table 1. MALDI-TOF MS identification and phenotypic characterization of the coccoid-shaped isolates.

\begin{tabular}{|c|c|c|c|c|c|c|c|c|c|c|c|c|}
\hline \multirow{2}{*}{$\begin{array}{c}\text { MALDI-TOF } \\
\text { MS } \\
\text { identification }^{\mathrm{a}} \\
\text { Isolates }\end{array}$} & \multicolumn{11}{|c|}{ Pediococcus acidilactici } & \multirow{2}{*}{$\begin{array}{c}P . \\
\text { pentosaceus } \\
\mathrm{UN32}\end{array}$} \\
\hline & UN2 & UN13 & UN14 & UN18 & UN19 & UN20 & UN25 & UN26 & UN28 & UN29 & UN27, UN39, UN44 & \\
\hline Source & $\mathrm{C}$ & $\mathrm{B}$ & A & A & A & $\mathrm{C}$ & $\mathrm{C}$ & $\mathrm{B}$ & A & $\mathrm{C}$ & A & $\mathrm{B}$ \\
\hline $\mathrm{CO}_{2}$ from glucose & - & - & - & - & - & - & - & - & - & - & - & - \\
\hline Acid production ${ }^{\mathrm{b}}$ & $\begin{array}{c}(-/+) \\
c\end{array}$ & $(-/+)$ & $(-/+)$ & $(-/+)$ & $\begin{array}{c}(-/+) \\
w\end{array}$ & $(-/+)$ & $(-/+)$ & $(-/+)$ & $(-/+)$ & $(-/+)$ & $(-/+)$ & $(-/+)$ \\
\hline \multicolumn{13}{|l|}{ Sugar patterns } \\
\hline L-Arabinose & + & + & + & + & + & + & + & - & + & + & + & + \\
\hline Ribose & + & + & + & + & + & + & + & + & + & + & + & + \\
\hline D-Xylose & - & + & - & + & - & - & - & - & - & - & + & - \\
\hline Galactose & + & + & + & + & + & + & + & + & + & + & + & + \\
\hline D-Glucose & + & + & + & + & + & + & + & + & + & + & + & + \\
\hline D-Fructose & + & + & + & + & + & + & + & + & + & + & + & + \\
\hline D-Mannose & + & + & + & + & + & + & + & + & + & + & + & + \\
\hline Mannitol & - & - & - & - & - & - & - & - & - & - & - & - \\
\hline Sorbitol & - & - & - & - & - & - & - & - & - & - & - & + \\
\hline $\begin{array}{l}\text { N-Acethyl- } \\
\text { glucosamine }\end{array}$ & + & + & + & + & + & + & + & + & + & + & + & + \\
\hline Amygdalin & - & - & - & - & - & + & - & - & - & - & - & + \\
\hline Arbutin & - & - & - & + & - & + & - & - & - & - & - & + \\
\hline Esculin & - & + & - & + & + & + & + & - & + & + & + & + \\
\hline Salicin & - & + & - & + & - & + & - & - & - & - & + & + \\
\hline Cellobiose & + & + & + & + & + & + & + & + & + & + & + & + \\
\hline Maltose & - & - & - & - & - & - & + & - & - & - & - & + \\
\hline Lactose & - & - & - & - & - & - & - & - & - & - & - & - \\
\hline Melibiose & - & - & - & - & - & - & + & - & - & - & - & + \\
\hline Sucrose & - & - & - & - & - & - & + & - & - & - & - & + \\
\hline Trehalose & + & - & + & - & + & + & + & + & - & + & - & + \\
\hline D-Raffinose & - & - & - & - & - & - & + & - & - & - & - & + \\
\hline Starch & - & - & - & - & - & - & - & - & - & - & - & - \\
\hline$\beta$-Gentobiose & + & + & + & + & + & + & + & + & + & + & + & + \\
\hline D-Lyxose & - & - & - & - & - & - & - & - & - & - & - & - \\
\hline D-Tagatose & + & + & + & + & + & + & + & + & + & + & - & - \\
\hline
\end{tabular}

Source of the isolates: (A) millet gruel (baca), (B) fermented millet dough for wômi production, (C) fried millet cake (wômi)

${ }^{\text {a }}$ Identification by species mass spectra

${ }^{\mathrm{b}}$ Based on acid production on homofermentative-heterofermentative differential (HHD) agar medium

c (-/+) White colonies with a blue spot on an acidified HHD agar

w: weak acidification

+: positive/-: negative for the test 
Table 2. MALDI-TOF MS identification and phenotypic characterization of the rod-shaped isolates.

\begin{tabular}{|c|c|c|c|c|c|c|c|}
\hline \multirow{2}{*}{$\begin{array}{c}\begin{array}{c}\text { MALDI-TOF MS } \\
\text { identification }^{\text {a }}\end{array} \\
\text { Idolates }\end{array}$} & \multicolumn{5}{|c|}{ Lactobacillus fermentum } & \multirow{2}{*}{$\begin{array}{c}\begin{array}{c}\text { L. plantarum } \\
\text { subsp plantarum }\end{array} \\
\text { UN47 }\end{array}$} & \multirow{2}{*}{$\begin{array}{c}\text { L. salivarius } \\
\text { UN6 }\end{array}$} \\
\hline & UN3 & UN5, UN16 & UN33 & UN35 & UN37, UN49 & & \\
\hline Source & A & B $\mathrm{C}$ & A & $\mathrm{B}$ & C B & $\mathrm{B}$ & A \\
\hline $\mathrm{CO}_{2}$ from glucose & + & + & + & + & + & - & - \\
\hline Acid production ${ }^{b}$ & $(-)^{c}$ & $(-)$ & $(-)$ & $(-)$ & $(-)$ & $(-/+)^{d}$ & $(+){ }_{\mathrm{w}}^{\mathrm{e}}$ \\
\hline \multicolumn{8}{|l|}{ Sugar patterns } \\
\hline L-Arabinose & + & - & + & + & + & - & - \\
\hline Ribose & + & + & + & + & + & + & - \\
\hline D-Xylose & + & + & + & + & + & - & - \\
\hline Galactose & + & + & + & + & + & + & + \\
\hline D-Glucose & + & + & + & + & + & + & + \\
\hline D-Fructose & + & + & + & + & + & + & + \\
\hline D-Mannose & + & + & + & + & + & + & + \\
\hline Dulcitol & - & - & - & - & - & + & - \\
\hline Mannitol & - & - & - & - & - & + & + \\
\hline Sorbitol & - & - & - & - & - & + & + \\
\hline N-Acethyl-glucosamine & - & - & - & + & - & + & + \\
\hline Amygdalin & - & - & - & + & - & + & - \\
\hline Arbutin & - & - & - & + & - & + & - \\
\hline Esculin & + & - & - & + & - & + & - \\
\hline Salicin & - & - & - & + & - & + & - \\
\hline Cellobiose & + & - & - & + & - & + & - \\
\hline Maltose & + & + & + & + & + & + & - \\
\hline Lactose & + & + & + & + & + & + & + \\
\hline Melibiose & + & + & + & + & + & + & + \\
\hline Sucrose & + & + & + & + & + & + & + \\
\hline Trehalose & + & + & + & + & + & + & + \\
\hline D-Raffinose & + & + & + & + & + & + & + \\
\hline Starch & - & - & - & - & - & - & - \\
\hline$\beta$-Gentobiose & - & - & - & + & - & + & - \\
\hline D-Arabitol & - & - & - & - & - & + & - \\
\hline Gluconate & + & + & - & + & + & + & - \\
\hline 2-Keto-gluconate & - & - & - & - & - & - & - \\
\hline 5-Keto-gluconate & + & + & - & + & + & - & - \\
\hline
\end{tabular}

Source of the isolates: (A) Millet gruel (baca), (B) fermented millet dough for wômi production, (C) fried millet cake (wômi)

${ }^{a}$ Identification by species mass spectra

${ }^{\mathrm{b}}$ Growth and acid production on homofermentative-heterofermentative differential (HHD) agar medium

c (-) White colonies on a blue HHD agar medium

d (-/+) White colonies with a blue spot on an acidified HHD agar medium

${ }^{\mathrm{e}}(+)$ Blue colonies on an acidified HHD agar medium

w: weak acidification

+: positive/-: negative for the test

The sugar fermentation patterns of the isolates were accessed using the API 50 CHL test (Tables 1, 2). All the isolates related to $P$. acidilactici, $P$. pentosaceus, $L$. fermentum, L. salivarius and L. plantarum subsp. plantarum were able to ferment galactose, D-glucose, D-fructose and D-mannose. All homofermentative coccoid shaped isolates 


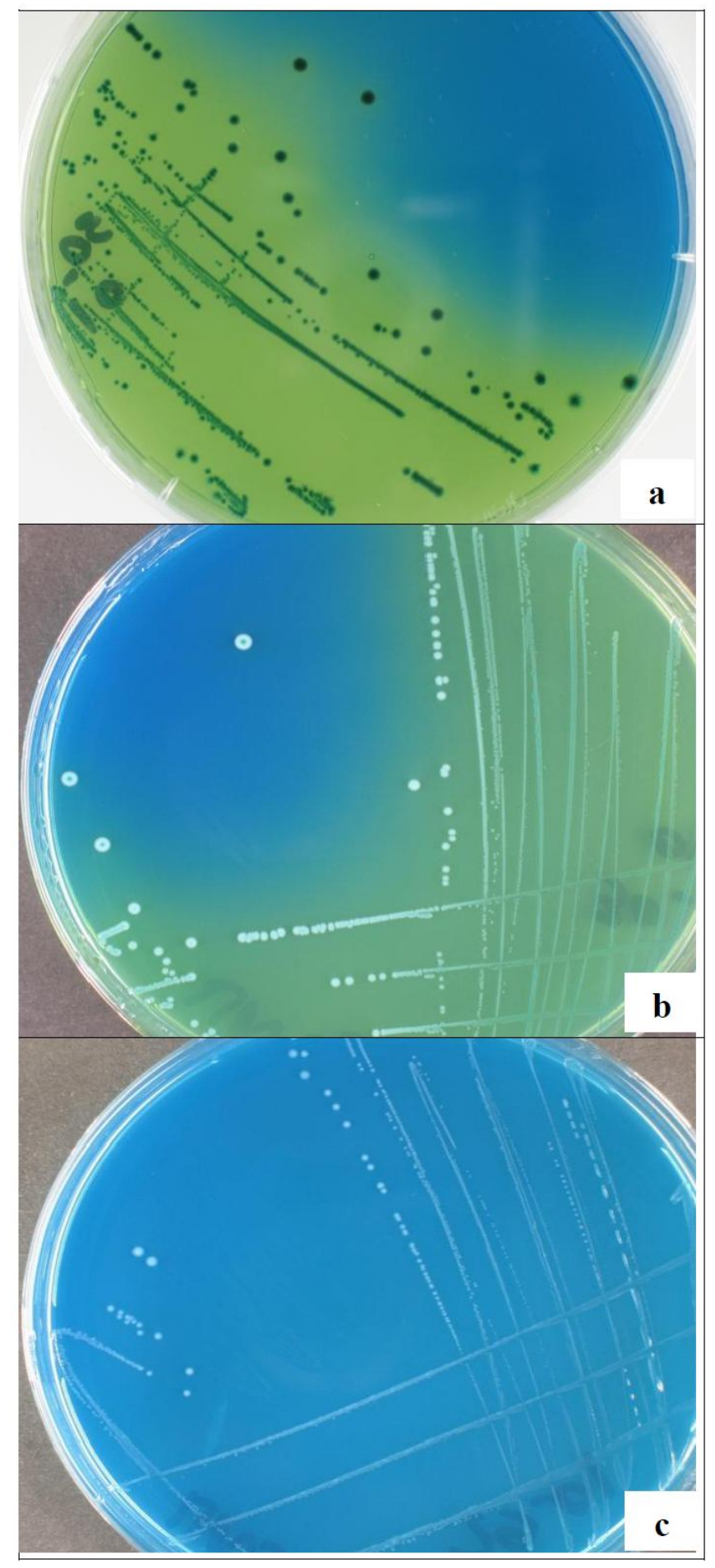

Fig. (4). Growth and acidification on homofermemtativeheterofermentative differential (HHD) agar medium of isolates UN6 (a), UN29 (b), and UN5 (c)

were not able to produce acid from D-arabinose or L-lyxose. Both pentoses are found rarely in nature only. L-arabinose was in contrast widespread among crop products and could be fermented from all strains except UN 26. All coccoid strains were able to ferment ribose in addition, and D-xylose was utilized from 5 strains only. Hexoses like galactose, Dglucose, D-fructose, D-mannose, $\mathrm{N}$-acetyl-glucosamine were fermented from all strains and 10 strains were also able to produce acid from D-tagatose (Table 1). From the disaccharides tested, cellobiose and $\beta$-gentobiose were utilized from all strains. Reaction for trehalose was variable among the isolates. Only two strains, UN25 and UN 32, were able to ferment melibiose. The same was true for the polysaccharide D-raffinose. Strain UN 32 was the only one able to ferment sorbitol. UN32 showed a typical metabolic profile of a Pediococcus pentosaceus strain, whereas as all other profiles were more related to Pediococcus acidilactici; except that the profile of strain UN25 was also closely related to $P$. pentasocaeus caused by the ability to ferment maltose, melibiose, sucrose and D-raffinose. Furthermore only two strains, UN20 and UN32, were able to ferment all of the glucosids (amygdalin, arbutin, esculin and salicin) included in the test kit. Taken together more than $77 \%$ of the coccoid strains were able to ferment L-arabinose, and Dtagatose. Trehalose, salicin, D-xylose, D-tagatose and amygdalin were fermented by $65 \%, 46 \%, 38 \%, 18 \%$ and $8 \%$ of them, respectively. All the isolates related to $P$. acidilactici showed a similar sugar pattern to that reported previously, despite the use of amygdalin and L-fucose by only $8 \%$ and none of them, respectively [5]. The isolate related to $P$. pentosaceus, which did not ferment D-tagatose, was able to ferment more sugars (e.g., sorbitol, sucrose and D-raffinose). Within the $P$. acidilactici isolates, it is possible that UN 25 was related to $P$. pentosaceus because it was able to ferment D-raffinose. Pediococcus acidilactici and $P$. pentosaceus were difficult to discriminate using biochemical tests because they were more closely related to each other than to other pediococci species [30].

All the isolates related to $L$. fermentum were able to ferment most of the hexoses, pentoses and disaccarides, except D-arabinose, L-sorbose and D-turanose. (Table 2). More than $70 \%$ of them were able to ferment L-arabinose, gluconate and 5-keto-gluconate. Eighty-six percent and 71\% of them fermented gluconate and 5-keto-gluconate, respectively. Only two strains isolate UN3 and UN35 were able to ferment cellobiose and esculin The isolate UN35 showed a more distantly related profile as compared to the other obligately heterofermentative rod-shaped isolates. This strain was able to utilize all glucosides, N-acetylglucosamin, and B-gentobiose. The two homofermentative strains showed a completely different metabolic profile. Mannitol, sorbitol, N-acethyl-glucosamine and D-raffinose were fermented by the L. salivarius isolate (UN6), which was unable to ferment all the 5-carbon sugars tested (e.g., arabinose, ribose and xylose). The L. plantarum subsp. plantarum isolate (UN47) was able to ferment dulcitol, mannitol and D-arabitol that were not fermented by any of the other isolates. The sugar fermentation pattern of the isolates related to L. fermentum was similar to that reported previously, and the isolate UN35 could be related to $L$. fermentum (biotype cellobiosus) [5, 31]. Riboprinting also indicated that the DNA fingerprint of strain UN35 was more related to strain DSM 20055 as compared to the type strain of Lactobacillus fermentum DSM 20052 ${ }^{\mathrm{T}}$. The species Lactobacillus cellobiosus (type strain DSM 20055 ${ }^{\mathrm{T}}$ ) have been reclassified as a later heterotypic synonym of Lactobacillus fermentum [32]. Based on high 16S rRNA and recA gene sequence similarity L.cellobiosus was assigned to the species L.fermentum. 
The isolate UN6 related to $L$. salivarius was able to ferment all the sugars reported previously for the same species, except maltose [5]. The isolate UN47 showed a similar sugar pattern to that reported for $L$. plantarum species and L. plantarum subsp. argentoratentis DKO $22^{\mathrm{T}}$ isolated from sour cassava, although there were some differences [33, 34]. This isolate was able to ferment more sugars (e.g., dulcitol, sorbitol, arbutin, D-arabitol and 2-ketogluconate), but it did not ferment mannitol. Inter-strain variability in fermentation ability could explain the differences in sugar patterns among isolates of the same species [35]. The API 50 CHL test, together with the Durham test and acid production on HHD agar medium, could be used for a rapid phenotypic screening of LAB, based on the great similarity in the results provided by each of them. At least one of the 5-carbon sugars tested (e.g. arabinose, ribose and xylose) was fermented by all the isolates related to $P$. acidilactici, $P$. pentosaceus, $L$. fermentum and $L$. plantarum subsp. plantarum, whereas none of them was fermented by the obligately homofermentative isolate UN6, related to L. salivarius.

MALDI-TOF MS identification of the isolates corresponded with that provided by the phenotypic characterization. MALDI-TOF MS protein analysis was also useful for differentiating L. fermentum strains (UN 37, UN 49), which showed similar sugar patterns. Identification based on biochemical tests was related more to metabolic functions than to genetic proximity [7]. MALDI-TOF MS protein analysis provided accurate identification as well as a high level of discrimination among isolates from fermented cereal foods available in Abidjan. We suggest that it could be used for the accurate and rapid screening of LAB starter cultures in general. Microbial investigation of the various fermented cereal food samples resulted into the detection of two homofermentative Lactobacillus strains. Homofermenters produce lactate efficiently from the fermentation of glucose. Acidification and acid tolerance of a starter culture is important for the fermentation process itself. Notably strain UN47 was able to ferment most of the disaccharides. The combination of biochemical testing and MALDI-TOF could efficiently be used for quick identification and selection of ideal candidates to be adapted as starter cultures for cereal fermentation foods.

\section{CONFLICT OF INTEREST}

The authors declare that they have no conflict of interest with regard to the subject matter of this paper.

\section{ACKNOWLEDGMENTS}

This work was supported by research grants from the International Foundation for Science (IFS, E/4953-1/2) and The World Academy of Sciences (TWAS, FR:3240262723). Soro-Yao A. was supported by the TWAS-German Research Foundation (DFG) cooperation visits program for scientists from sub-Saharan Africa. The authors wish to thank Prof. Jörg Overmann for the fulfillment of Dr. Soro-Yao postdoctoral stay at the German Collection of Microorganisms and Cell Cultures (DSMZ, Germany) as well as Iris Brandes, Melanie Duckstein and Anika Wasner for their excellent technical assistance.

\section{REFERENCES}

[1] Soro-Yao AA, Brou K, Koussémon M, Djè KM. Proximate composition and microbiological quality of millet gruels sold in Abidjan (Côte d'Ivoire). Int J Agr Inov Res 2014; 2: 472-9.

[2] Soro-Yao AA, Brou K, Koffi-Nevry R, Djè KM. Microbiology of Ivorian fermented products: A review. Asian J Agr Food Sci 2013; 1: 37-47.

[3] Yao AA, Dortu C, Egounlety M, et al. Production of freeze-dried lactic acid bacteria starter culture for cassava fermentation into gari. Afr J Biotechnol 2009; 8: 4996-5004.

[4] Adimpong B, Nielsen DS, Sørensen KI, Derkx PMF, Jespersen L. Genotypic characterization and safety assessment of lactic acid bacteria from indigenous African fermented products. BMC Microbiology 2012; 12: 15-27.

[5] Hounhouigan DJ, Nout MJR, Nago CM, Houben JH, Rombouts FM. Composition and microbiological and physical attributes of mawè, a fermented maize dough from Benin. Int J Food Sci Tech 1993; 28: 513-17.

[6] Lei V, Jakobsen M. Microbiological characterization and probiotic potential of koko and koko sour water, African spontaneously fermented millet porridge and drink. J Appl Microbiol 2004; 96: 384-97.

[7] Obinna-Echem PC, Kuri V, Beal J. Evaluation of the microbial community, acidity and proximate composition of akamu, a fermented maize food. J Sci Food Agric 2014; 94: 331-40.

[8] Oguntoyinbo FA, Narbad A. Molecular characterization of lactic acid bacteria and in situ amylase expression during traditional fermentation of cereal foods. Food Microbiol 2012; 31: 254-62.

[9] Oguntoyinbo FA, Tourlomousis P, Gasson MJ. Analysis of bacterial communities of traditional fermented West African cereal foods using culture independent methods. Int J Food Microbiol 2011; 145: 205-10.

[10] Owusu-Kwarteng J, Akabanda F, Nielsen DS, Tano-Debrah K, Glover RLK, Jespersen L. Identification of lactic acid bacteria isolated during traditional fura processing in Ghana. Food Microbiol 2012; 32: 72-8.

[11] Vieira-Dalodé G, Jespersen L, Hounhouigan DJ, Moller PL, Nago $\mathrm{CM}$, Jakobsen M. Lactic acid bacteria and yeasts associated with gowé production from sorghum in Bénin. J Appl Microbiol 2007; 103: 342-9.

[12] Doan NTL, Van Hoorde K, Cnockaert M, et al. Validation of MALDI-TOF MS for rapid classification and identification of lactic acid bacteria, with a focus on isolates from traditional fermented foods in Northern Vietnam. Lett Appl Microbiol 2012; 55: $265-73$.

[13] Prohaska S, Pflüger V, Ziegler D, et al. MALDI-TOF MS for identification of porcine Brachyspira species. Lett Appl Microbiol 2014; 58: 292-8.

[14] Herbel SR, Vahjen W, Wieler LH, Guenther S. Timely approaches to identify probiotic species of the genus Lactobacillus. Gut Pathogens 2013; 5: 27-40.

[15] Mohania D, Nagpal R, Kumar M, et al. Molecular approaches for identification and characterization of lactic acid bacteria. J Dig Dis 2008; 9: 190-8.

[16] Cherkaoui A, Hibbs J, Emonet S, et al. Comparison of two matrixassisted laser desorption ionization-time of flight mass spectrometry methods with conventional phenotypic identification for routine identification of bacteria to the species level. J Clin Microbiol 2010; 48: 1169-75.

[17] Pavlovic M, Huber I, Konrad R, Busch U. Application of MALDITOF MS for the identification of food borne bacteria. Open Microbiol J 2013; 7: 135-41. 
[18] Nguyen DTL, Van Hoorde K, Cnockaert M, et al. A description of the lactic acid bacteria microbiota associated with the production of traditional fermented vegetables in Vietnam. Int J Food Microbiol 2013; 163: 19-27.

[19] Angelakis E, Million M, Henry M, Raoult D. Rapid and accurate bacterial identification in probiotics and yoghurts by MALDI-TOF Mass Spectrometry. J Food Sci 2011; 76: M568-71.

[20] Ruiz-Moyano S, Tao N, Underwood MA, Mills DA. Rapid discrimination of Bifidobacterium animalis subspecies by matrixassisted laser desorption ionization time of flight (MALDITOF) Mass Spectrometry. Food Microbiol 2012; 30: 432-7.

[21] Tanigawa K, Kawabata H, Watanabe K. Identification and typing of Lactococcus lactis by matrix-assisted laser desorption ionization-time of flight mass spectrometry. Appl Environ Microbiol 2010; 76: 4055-62.

[22] Schumann P, Pukall R. The discriminatory power of ribotyping as automatable technique for differentiation of bacteria. Syst Appl Microbiol 2013; 36: 369-75.

[23] Kongo JM, Ho AJ, Malcata FX, Wiedmann M. Characterization of dominant lactic acid bacteria isolated from Sa o Jorge cheese, using biochemical and ribotyping methods. J Appl Microbiol 2007; 103: $1838-44$.

[24] Larpent-Gourgaud M, Larpent J-P. Manuel pratique de Microbiologie. 1 st ed. Hermann Publishers and Distributors: Paris 1985.

[25] Mcdonald LC, Mcfeeters MA, Daeschel MA, Fleming HP. A differential medium for the enumeration of homofermemtative and heterofermentative lactic acid bacteria. Appl Env Microbiol 1987; 53: $1382-4$.

[26] Tóth EM, Schumann P, Borsodi AK, Kéki Z, Kovács AL, Márialigeti K. Wohlfahrtiimonas chitiniclastica gen. nov., sp. nov., a new gammaproteobacterium isolated from Wohlfahrtia magnifica (Diptera: Sarcophagidae). Int J Syst Evol Microbiol 2008; 58: 97681.
[27] Bruce J. Automated system rapidly identifies and characterizes microorganisms in food. Food Technol 1996; 50: 77-81.

[28] Stackebrandt E, Breymann S, Steiner U, Prauser H, Weiss N, Schumann P. Re-evaluation of the status of the genus Oerskovia, reclassification of Promicromonospora enterophila (Jáger et al., 1983) as Oerskovia enterophila comb. nov. and description of Oerskovia jenensis sp. nov. and Oerskovia paurometabola sp. nov. Int J Syst Evol Microbiol 2002; 52: 1105-11.

[29] Songré-Ouattara LT, Mouquet-Rivier C, Verniere C, Humblot C, Diawara B, Guyot JP. Enzyme activities of lactic acid bacteria from a pearl millet fermented gruel (ben-saalga) of functional interest in nutrition. Int J Food Microbiol 2008; 128: 395-400.

[30] Holzapfel WH, Franz CMAP, Ludwig W, Back W, Dicks LMT. The genera Pediococcus and Tetragenococcus. Prokaryotes 2006; 4: 229-66.

[31] Agati V, Guyot JP, Morlon-Guyot J, Talamond P, Hounhouigan DJ. Isolation and characterization of new amylolytic strains of Lactobacillus fermentum from fermented maize doughs (mawé and ogi) from Benin. J Appl Microbiol 1998; 85: 512-20.

[32] Dellaglio F, Torriani S, Felis GE. Reclassification of Lactobacillus cellobiosus Rogosa et al. 1953 as a later synonym of Lactobacillus fermentum Beijerinck 1901. Int J Syst Evol Microbiol 2004; 54: 809-12.

[33] Bringel F, Castioni A, Olukoya DK, Felis GE, Torriani S, Dellaglio F. Lactobacillus plantarum subsp. argentoratensis subsp. nov., isolated from vegetable matrices. Int J Syst Evol Microbiol 2005; 55: $1629-34$.

[34] Kostinek M, Specht I, Edward VA, et al. Diversity and technological properties of predominant lactic acid bacteria from fermented cassava used for the preparation of Gari, a traditional African food. Syst Appl Microbiol 2005; 28: 527-40.

[35] Sawadogo-Lingani H, Diawara B, Glover RK, Tano-Debrah K, Traoré AS, Jakobsen M. Predominant lactic acid bacteria associated with the traditional malting of sorghum grains. Afr $\mathbf{J}$ Microbiol Res 2010; 4: 169-79.

(C) Soro-Yao et al.; Licensee Bentham Open.

This is an open access article licensed under the terms of the Creative Commons Attribution Non-Commercial License (http://creativecommons.org/licenses/by-nc/3.0/) which permits unrestricted, non-commercial use, distribution and reproduction in any medium, provided the work is properly cited. 